\title{
On the Spatio-Temporal Under-Representation of Isotopic Data in Ecohydrological Studies
}

\author{
Matthias Beyer ${ }^{1 *}$ and Daniele Penna ${ }^{2}$ \\ ${ }^{1}$ Department of Architecture, Civil Engineering and Environmental Sciences, Institute of Geoecology (IGÖ), Technical \\ University of Braunschweig, Braunschweig, Germany, ${ }^{2}$ Department of Agriculture, Food, Environment and Forestry (DAGRI), \\ University of Florence, Florence, Italy
}

Keywords: stable isotopes of hydrogen and oxygen, critical zone, ecohydrology, plant water uptake, heterogeneity, isotope hydrology, isotope ecohydrology

\section{HETEROGENEITY AND UNCERTAINTY IN ISOTOPE-BASED ESTIMATES OF PLANT WATER UPTAKE}

\section{It's a Messy World!}

Achieving a holistic understanding of water sources used by plants is of great importance for water resources management in vegetated ecosystems under changing climatic conditions.

OPEN ACCESS

Edited by:

Yunpeng Nie,

Chinese Academy of Sciences

(CAS), China

Reviewed by:

James Knighton,

University of Connecticut,

United States

Erik Oerter,

United States Department of Energy

(DOE), United States

*Correspondence:

Matthias Beyer

matthias.beyer@tu-bs.de

Specialty section

This article was submitted to Water and Critical Zone, a section of the journal

Frontiers in Water

Received: 17 December 2020 Accepted: 09 February 2021

Published: 11 March 2021

Citation:

Beyer M and Penna D (2021) On the

Spatio-Temporal

Under-Representation of Isotopic Data in Ecohydrological Studies.

Front. Water 3:643013.

doi: 10.3389/frwa.2021.643013
Reliable estimates of the proportions of water taken up by plants are crucial both in smalland in large-scale studies. The former are typically investigations carried out on individual trees to assess the ecohydrological (defined here as the bilateral relation between water and the vegetation compartment of ecosystems) and physiological response of vegetation to environmental stressors; studies at larger scales focus, for instance, on catchment- or forest-centered analysis of evapotranspiration and/or surface and subsurface water fluxes movements.

Since many decades, stable isotopes of hydrogen and oxygen $\left({ }^{2} \mathrm{H}\right.$ and $\left.{ }^{18} \mathrm{O}\right)$ in the water molecule have proved valuable tools to quantify root water uptake and to assess transport processes and ecohydrological dynamics in forested catchments (recent examples: Allen et al., 2019; Evaristo et al., 2019; Knighton et al., 2020; Juhlke et al., 2021), and in agroforestry and agricultural ecosystems (Huo et al., 2020; Muñoz-Villers et al., 2020; Penna et al., 2020 and references therein). Despite the noteworthy advancements that the isotope technique added to the field of ecohydrology, recent research has questioned the reliability of many isotope-based plant water sourcing studies due to the discovery of several effects that prevent a robust quantification of the fractional contributions of different water sources to plant transpiration. In some cases, these effects can lead to biases and possibly incorrect interpretation of the results even at small scales. Some of these issues have been discussed in recent works (Penna et al., 2018; Barbeta et al., 2019, 2020; Beyer et al., 2020; Sprenger and Allen, 2020; Von Freyberg et al., 2020) but in this opinion paper we aim at summarizing them in a comprehensive way and stimulating community efforts to address uncertainty in isotope-base studies of vegetation water sources and uncertainty propagation across spatial scales.

In essence, the world is intrinsically enormously heterogeneous (Pfister and Kirchner, 2017; Oerter and Bowen, 2019; Penna and van Meerveld, 2019), and heterogeneity is responsible for the spatio-temporal variability of hydrological and ecohydrological states as well as scale-dependent flow and transport properties (Troch et al., 2009). For ecohydrological systems, we distinguish here between structural heterogeneity (physical structure of soils and plants) and process heterogeneity (physical and physiological processes in soils and plants).

We focus on three main aspects: (i) difficulties in addressing and capturing the (isotopic) heterogeneity of ecohydrological systems; (ii) physical and physiological effects that can alter the isotopic composition of soil and plant xylem water; and (iii) technical aspects for extracting water samples from soils and plants, and laboratory analysis for isotopic composition. 
As for point (i) on difficulties in characterizing the isotopic heterogeneity of ecohydrological systems, different, wellestablished (see the review by Rothfuss and Javaux, 2017) or recently investigated (e.g., Amin et al., 2020) isotopebased methods can be applied to estimate the proportions of root water uptake by plants. The latest generation of mixing models is capable of including heterogeneity into the computed proportions of water sources (Parnell et al., 2010). However, this estimation is typically based on replicate samples (e.g., of one soil core or xylem samples from the same plant), not including the real spatial or temporal heterogeneity. Most of these methodsif not all-rely on homogeneity assumptions, i.e., a relative lack of variability (especially in space) of the isotopic composition of end-members (e.g., soil water, groundwater, rain water) and/or lack of distinct characteristics of structures and processes of soils and plants. Typically, root water uptake is treated conceptually as a function of soil depth; i.e., a vertically stacked system where lateral heterogeneity (in flow paths, water content, and isotope composition) is often neglected (Oerter et al., 2019). The ecohydrological community now knows that this view does not represent the reality in many cases. But how can researchers objectively define relevant end-members when moving into $3 \mathrm{D}$ space (e.g., vertical vs. horizontal discretization, maximum soil depth, morphology, pore sizes)?

In addition to this challenge, another critical point is that the isotopic characterization of the deeper soil (e.g., below $1 \mathrm{~m}$ ) is often insufficient. All soil properties and the water isotopic composition below the maximum sampling depth are often lumped under the "deep soil" and/or "groundwater" concept, using the respective isotope value of the deepest layer sampled, or of groundwater. Consequently, the true maximum uptake depth cannot be inferred, leading to an additional source of uncertainty. This problem could be faced and mitigated knowing the maximum rooting depth of a given plant, as this would provide hints on how deep it might be necessary to sample. Unfortunately, this is almost never the case and studies using such assumptions might be biased as well.

As for point (ii) on physical and physiological effects that can modify the isotopic composition of water in soil and plant water, several of these effects were recently described and often associated with soil and plant heterogeneity. Consequently, the two issues on isotopic heterogeneity characterization and alteration effects [points (i) and (ii) reported above] can be merged. As a result, we can define two main groups of effects that combine with each other and generate uncertainty in isotopebased estimates of water sources for vegetation root water uptake: (1) natural and (2) artificial effects (Figure 1), where natural effects include both the heterogeneity associated with the physical, chemical, and biochemical structure of soils and plants, and the heterogeneity associated with the physical and physiological processes in plants and soils. Without any claim of completeness, we list the main following effects for each group (Figure 1):

(1) Natural effects (NAT in Figure 1) include all elements related to structural and process heterogeneity of ecohydrological systems, as follows: a) Spatial and seasonal variability in the isotopic composition of precipitation; amount effect; recycling during thunderstorms (e.g., Araguás-Araguás et al., 2000; Sánchez-Murillo et al., 2019).

b) Processes related to the alteration of the precipitation isotopic signal due to the effect of canopy and understory interception and redistribution (Allen et al., 2014, 2015, 2017; Dubbert et al., 2014; Stockinger et al., 2017).

c) Lag time from water input (precipitation and/or irrigation) to output, i.e., water traveling from precipitation and/or irrigation via soils to roots to stems to twigs to leaves (Cermak et al., 2007; Brinkmann et al., 2018; Von Freyberg et al., 2020).

d) Possible fractionation during root water uptake (e.g., Vargas et al., 2017; Poca et al., 2019; Barbeta et al., 2020) and post-uptake processes in the plant such as: fractionation for sections close to the leaf-atmosphere interface; back diffusion (enriched water that diffuses back to the xylem, often in green stems that contain stomata or lenticel); presence of mycorrhizal fungi (Poca et al., 2019; Barbeta et al., 2020).

e) Anatomical properties and related processes such as vein structure, phloem-xylem exchange, non-steady-state transpiration, foliar uptake, hydraulic redistribution, plant water storage (Brooks et al., 2002; Hafner et al., 2017; Körner, 2019); possible differences in isotopic composition of heartwood and sapwood (Berry et al., 2019).

f) Plant traits such as species, age, size, leaf area index, specific leaf area, and root plasticity (Dubbert and Werner, 2019).

g) Soil evaporation, different size of soil pores, and related complex flow pathways (mixing processes between soil water of different layers, and between water in the unsaturated rootzone and in the saturated zone; capillary rise) resulting in non-monotonic water age and isotope soil profiles (Sprenger and Allen, 2020; Von Freyberg et al., 2020).

h) Mineral-mediated fractionation in soil samples (Oerter et al., 2014; Gaj et al., 2017). This is a natural effect although its impact on the isotopic composition of soil water is mainly exhibited during water extraction processes from soil samples (see point 2a below).

(2) Artificial effects (ART in Figure 1) mainly include soil and xylem water field sampling and extraction methods as well as instrumental measurement uncertainty in laboratory analysis, as follows:

a) Different methods for soil water sampling and extraction, such as tension lysimeters and cryogenic vacuum distillation returning different isotopic composition from the same sample (Geris et al., 2015; Orlowski et al., 2016, 2018, 2019).

b) Different methods for plant water sampling and extraction such as cryogenic vacuum distillation, Scholander-type pressure chamber, and other destructive methods possibly producing artifacts and returning different isotope values (Thoma et al., 2018; Fischer et al., 2019; Zuecco et al., 2020), preferentially affecting ${ }^{2} \mathrm{H}$ rather than ${ }^{18} \mathrm{O}$ values (Chen et al., 2020). Moreover, these destructive methods might not be able to sample the accessible (or mobile) water as in-situ methods do (e.g., Oerter et al., 2019). 


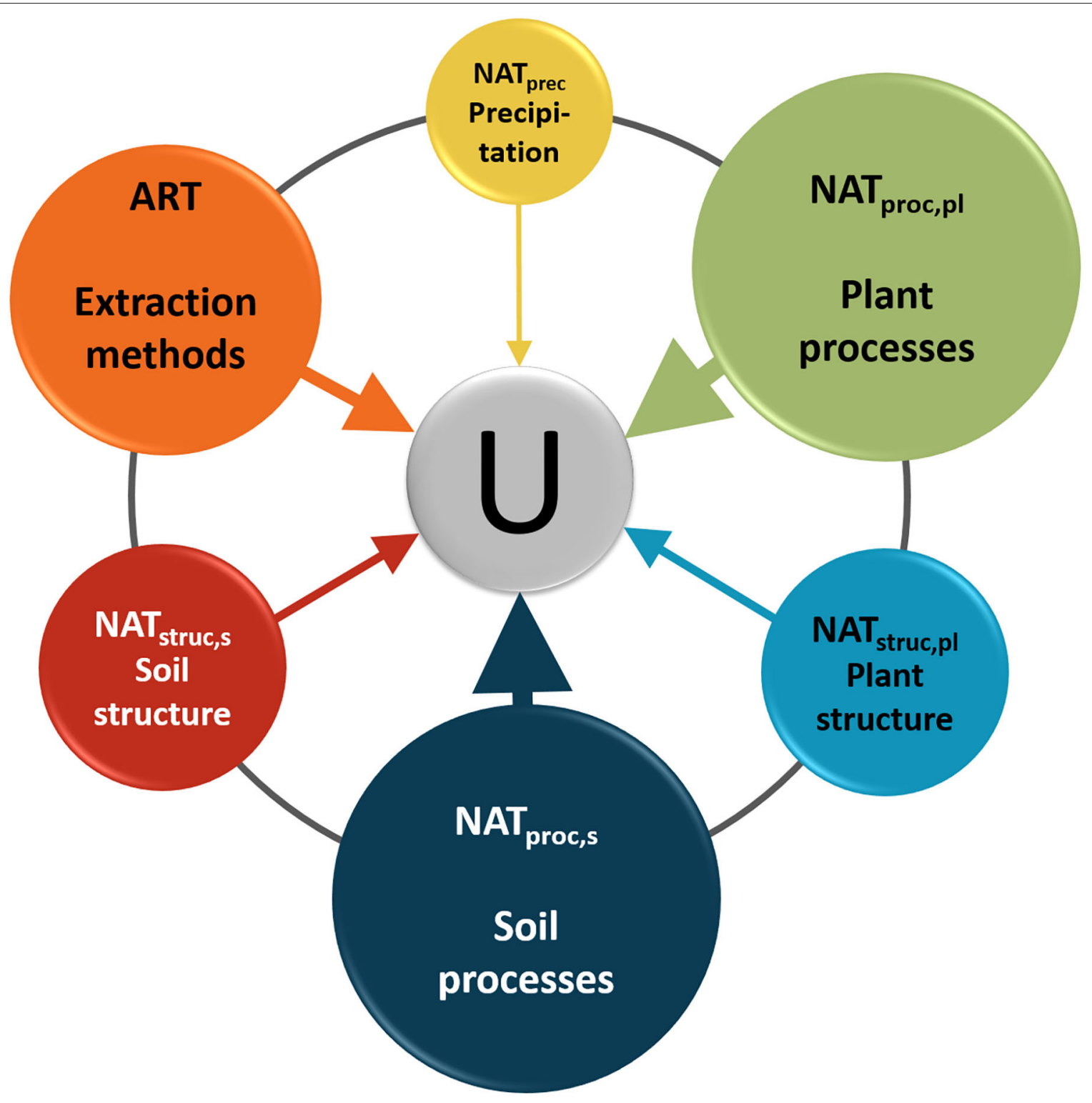

FIGURE 1 | Schematic conceptual representation of the natural (NAT) and artificial (ART) effects that cause uncertainty (U) in isotope-based estimates of plant water sources. NAT prec refers to point (1a) listed in the text; NAT proc,pl refers to points (1b-d); NAT struc,pl refers to points (1e and f); NAT proc,s and NAT struc,s refer to points (1g) and (1h), respectively; and $A R T$ refers to points $(2 \mathrm{a}-\mathrm{c})$. Plant and soil structure are characterized by the structural heterogeneity of ecohydrological systems, whereas plant and soil processes are characterized by the heterogeneity of the process. The dark gray line connecting all circles conceptually represents the links between all effects. Note that this line connects adjacent circles for visual clarity purposes only and that existing physical and physiological links between most of the circles (e.g., between plant structure and soil structure, between plant processes and soil processes, and between precipitation and soil structure and processes) are omitted to improve the figure readability. The difference in the size of the circles implies the subjectively estimated importance of individual effects on the combined uncertainty. $N A T_{\text {prec }}$ is depicted with the smallest circle despite the large spatial and temporal variability of its isotopic composition because current sampling designs and technical approaches allow capturing this variability relatively well. We are well aware that accounting for all these sources of uncertainty in isotope-based estimates of water sources used by vegetation is not possible but at least the key ones (i.e., the largest circles) should not be neglected and, if not quantified, mentioned and considered in ecohydrological studies.

c) Instrumental precision, repeatability, memory effects of isotope ratio mass spectrometry and laser spectroscopy measurements of water samples, possible off-set and deviations between mass spectrometry and laser spectroscopy measurements (Penna et al., 2010, 2012; Wassenaar et al., 2014; Wang et al., 2020), as well as contamination issues with organic compounds in laser spectroscopy (West A. G. et al., 2010; Martín-Gómez et al., 2015).

\section{How Reliable are our Estimates?}

The uncertainty resulting from natural and artificial effects (Figure 1) can be large but difficult to assess. Indeed, the overall 
uncertainty in isotope-based estimated proportions of sources for plant water use is rarely quantified. Methods that include uncertainty propagation exist (e.g., Moore and Semmens, 2008; Parnell et al., 2010, 2013; Rothfuss and Javaux, 2017; Bowen et al., 2018; Benettin et al., 2021) but they often rely on assumptions that are difficult to verify and meet (e.g., no fractionation during root water uptake, homogeneity of soil water isotope profiles at depth, knowledge of all water sources). Attempts to quantify uncertainty have been carried out but addressing only a limited part of the effects presented in Figure 1 (e.g., Evaristo et al., 2015; Zhang et al., 2017; Beyer et al., 2018). These considerations lead to a question: How reliable are isotope-based estimates of the proportions of different sources contributing to root water uptake? The answer is simple (and worrying): we, as a scientific community, do not have a clear knowledge about the degree of uncertainty that might affect our estimates. Very likely, this lack of awareness is strictly related to the nature of the methods themselves as it is extremely difficult to verify the estimated water uptake proportions through the application of any other method, i.e., it is impossible to measure. Ecohydrologists can often obtain general and useful insights on which water source plants use, but the exact proportions often remain obscure. Despite that, such exact values have been vastly used and reported as truth in past studies.

So, we argue here that ecohydrologists might use a method that is physically and mathematically meaningful and robust but that lacks experimental corroboration. The way forward to make isotope-based estimates more reliable is not easy, and we think that community efforts are needed to make progress. Advancements could be made by conducting quantitative assessments of the validity of the existing methods through laboratory or controlled experiments (e.g., in pots, in greenhouses, by application of labeled water).

\section{TEMPORAL}

\section{UNDER-REPRESENTATIVENESS}

\section{Go for in situ!}

Ecohydrological systems are dynamic and often not in a steady state. Root water uptake depths may change rapidly, and a set of destructive samples for assessing plant water use only covers one point in time. This is a classic issue for isotopebased ecohydrological studies, as sample collection is often laborious and-in particular for plants-cannot be repeated as often as desired. Repetitive sampling of one particular plant increases the uncertainty of isotope values (heterogeneity) and may damage the plant. Hence, longer time-series but also shortterm high-resolution soil and plant water isotope datasets are rare (e.g., Beyer et al., 2018). After a decade of intensive development, in situ approaches for measuring soil and plant water isotopes in a high temporal resolution are now at a stage where they can be applied with confidence (e.g., Oerter et al., 2019, and see the review by Beyer et al., 2020), and we invite the community to test and utilize these methods in the field more often. Indeed, the potential of using in situ methods is immense, particularly when dynamic processes are of interest.
For instance, this approach is highly valuable (i) to monitor gradual (seasonal) environmental changes, e.g., the reaction of plants to rain events or the transition from dry-to-wet or wetto-dry seasons; (ii) to observe water travel times in the soilplant-atmosphere system; (iii) to assess diurnal ecophysiological patterns and/or investigate redistribution of water (e.g., hydraulic lift). Moreover, in situ studies applied to isotopic labeling experiments can provide a powerful combination to trace water transport processes between soils, plants, and the atmosphere. However, we recommend that users must carefully assess whether in situ methods and setups-especially in the case of technically sophisticated sensors-are suitable to the objective of any given study.

\section{HOW TO OVERCOME SPATIAL UNDER-REPRESENTATIVENESS OF ISOTOPE DATA?}

\section{Including Uncertainty and Going Larger}

When looking at the sources of uncertainty in small scale studies (Figure 1) it becomes evident that including all of the listed factors will result in a rather large, and most of all, not quantified uncertainty of any estimate. We believe that approaches to incorporate the uncertainty in mixing model and modeling exercises should be sought within the ecohydrological community to obtain more robust estimates at different spatial scales. These approaches should aim at incorporating at least the effects that contribute most to generate uncertainty (Figure 1) in mixing models and models for evapotranspiration partitioning, and available methods for uncertainty propagation should be applied more consistently. In physically-based models, randomness-based procedures to express uncertainty through a probabilistic interpretation (e.g., Monte-Carlo simulations)-a state-of-art procedure in climate and many hydrological modelscould be adopted.

At the larger scale, NAT (see Figure 1) plays an important role and will increase the overall uncertainty of any given study. Few isotope-based water uptake studies aiming at larger scales are existing at present. The methods used therein can be summarized as follows: (i) Upscaling through modeling approaches based on individual plants and/or small scale tracer-based analysis (e.g., Stumpp et al., 2012; Fatichi et al., 2016; Mastrotheodoros et al., 2019); (ii) Well-planned spatial and temporal sampling design (e.g., defining sampling transects or sampling grids, coverage of key species and different age groups, etc.), complementing isotope analysis with ancillary monitoring such as soil moisture and sap flow dynamics (as auspicated by Jackisch et al., 2020) and upscaling via the isoscapes-approach (e.g., West et al., 2008; Bowen, 2010; West J. B. et al., 2010; Cheesman and Cernusak, 2016; Goldsmith et al., 2018; Allen et al., 2019); (iii) Correlation of supplementary spatially high-resolution data (e.g., remote sensing-derived species counts, plant heights, etc.) and upscaling using the derived relationships (Hellmann et al., 2016a,b; Hellmann et al., 2015).

While option (i) might seem the easiest, most feasible, and is also the most popular, we emphasize that reliable modeling 
results require adequate input data in both space and time. At present, such data are only available when looking at a limited number of plant species, and using rather large simplifications and assumptions (refer to Knighton et al., 2019b and references therein). Most studies using isotope-enabled models are limited to one isotope (typically ${ }^{18} \mathrm{O}$ ). Apart from that, current largerscale models are not capable of including different root water uptake distributions (e.g., shallow rooters and deep rooters). Hence, modeling efforts should not only be directed to improving the temporal (Sprenger et al., 2019) but also the spatial representation of NAT.

The approaches (ii) and (iii) could constitute a remedy for upscaling but have rarely been thoroughly applied-or combinedup to present. In order to limit sampling and laboratory efforts for (ii), studies should be carefully designed from the beginning with the idea of providing useful data in space and time for upscaling (e.g., by accounting for requirements of geostatistical upscaling measures). Recently, Juhlke et al. (2021) proposed an innovative method to avoid extensive soil water isotope sampling to understand water uptake patterns of one tree species along an elevation gradient. Furthermore, methods for temporally highresolution measurements of water isotopes in soils and plants are now available (see Beyer et al., 2020; Marshall et al., 2020) and can be adapted to cover larger spatial areas as well.

Finally, new, low-cost technological devices (e.g., Arduinobased loggers, Wickert et al., 2019) can be used to equip large areas with sensors for ecohydrological measurements.

UAV (Unmanned Aerial Vehicle)-based technologies iii) allow image acquisition covering large areas with a spatial resolution as high as on the single leaf. If equipped with suitable cameras and carefully calibrated, valuable high-resolution, plantrelevant information at the catchment-scale can be obtained (e.g., vegetation indices, leaf temperatures, see for instance Marzahn et al., 2020). If robust correlations between different test trees at a particular location are developed (potentially also including water isotope values), UAV-based upscaling is a relatively simple but powerful approach. Furthermore, UAV technologies have evolved up to a point where even branch sampling from the canopy of any given tree is feasible (Charron et al., 2020). This would tremendously support the design of water isotope studies, as the user could literally "select" trees to be sampled for isotope analysis (e.g., all trees of a certain species, height, along an elevation gradient). Allen et al. (2019) used a helicopter to sample tree tissues from forests in Switzerland, but this method is not accessible nor affordable for many; in contrast, UAV-based sampling will be, soon. Indeed, several research groups are currently working on collecting water vapor samples using UAV for isotope analysis. While this technology is under development, it might open up a new avenue, especially for spatially distinct partitioning of evapotranspiration fluxes or Keeling-plot based approaches.

A fourth way (iv) is the possibility to use catchment-integrated signals that allow evaluating the impact of certain variables on large scales directly. In hydrological studies, for instance, streamflow is a meaningful catchment-integrated measure. In ecohydrological studies, the most common approach has been the separation of evapotranspiration into its components.
However, model sensitivity analysis to determine sources of root uptake in catchment process-oriented modeling studies is still underexploited. Few attempts in this direction revealed sensitivity of streamflow calibration to root water uptake and of stream water isotopic composition to mixing in the vadose zone (Kuppel et al., 2018; Knighton et al., 2019a,b), although in other cases partitioning of evapotranspiration fluxes did not impact the simulated stream water isotopic signal (Knighton et al., 2017). Inverse ecohydrological modeling methods (e.g., Knighton et al., 2019a) and, more generally, methods based on long-term data series and incorporated water mixing and isotopic composition simulations might allow bridging the gap between plot- and catchment-scale water fluxes without the necessity of extensive soil and plant water sampling.

An alternative approach that was recently introduced and that allows working at different spatial scales is the use of StorAge Selection functions (SAS, Rinaldo et al., 2015; Rodriguez and Klaus, 2019) based on tracers (such as isotopes of oxygen and hydrogen or cloride) to estimate the "age" of water taken up by roots at the plot (Evaristo et al., 2019; Knighton et al., 2019a; Smith et al., 2020) and catchment scale (Wilusz et al., 2017). SAS functions circumvent many of the drawbacks of mixing models and process-based modeling because an a priori definition of distinct end-members is not necessary, and only a reasonable representation of the control volume from which fluxes draw is needed. However, they introduce new issues such as the need to provide a shape of the age-selection function, which is often theoretically parametrized, and the availability of long-term time series of data inputs characterized by a high temporal resolution.

In the end, in order to make ecohydrological studies relevant in decision-making processes, we advocate including and combining methods that allow evaluation of vegetation water use at larger scales.

\section{Upscaling Issues: Not Only Trees!}

Bridging the gap between small- and catchment- or forestscale water fluxes also requires the incorporation of understory plant species. Vegetation does not only mean trees. Shrubs and grassland are important components of the vegetation structure in different ecosystems (e.g., savannah, high-elevation or highlatitude prairies). In semi-arid Namibia, for instance, Beyer et al. $(2016,2018)$ found that small shrubs developed roots deeper than four meters and were capable of surviving extended droughts without reducing transpiration. Similarly critical is understanding water sources for crops, important components of agroecosystems and essential for food production and irrigation management (Penna et al., 2020), and for plant species in urban and managed settings (e.g., Oerter and Bowen, 2017). Ecohydrologists have very limited knowledge on water sources exploited by the non woody-species in vegetated ecosystems and of their associated variability (but see Kulmatiski et al., 2010; Holdo et al., 2013; Warren et al., 2015). Particularly, we advocate that it is not correct to neglect their role in studies that upscale results from the single tree-scale or the forest plot-scale because, very likely, increasing the spatial scale includes also non-woody species, shrubs, and grass. 


\section{Concluding Remarks}

Heterogeneity in soil and plant structures and processes dominate ecohydrological systems. Ecohydrologists must live with this heterogeneity, accept its associated uncertainty, and be aware that it can hamper their efforts to simplify, categorize, and better understand physical and physiological processes related to the transfer and storage of water in vegetated ecosystems. On the one hand, we, as a community, should be realistic and cautious in building complex conceptual models that rely on uncertain results. This can only be done by communicating uncertainty. On the other hand, the ecohydrological community has to look for verification approaches that can show the potentials and limitations of small-scale or laboratory methods, and that can quantify the associated uncertainty in the estimated water sources. At the same time, the scientific community needs more comprehensive studies across different climates and vegetation types that can mitigate the spatio-temporal under-representation of isotope data in ecohydrological compartments in order to improve the understanding on water movements and availability through ecosystems. Particular attention should be directed toward defining sampling and measurement protocols that allow subsequent upscaling. Ecohydrologists need to improve methods in 1-D space for providing reliable estimates of water uptake by plants, and need to move into 2-D and 3-D space to avoid the risk of making gross mistakes when describing ecohydrological processes at the entire forest-scale based on detailed studies of a few trees only. At the same time, the ecohydrological community urgently needs to find ways to incorporate uncertainty in both small-scale (i.e., the tree-, stand-, plot-, hillslope-scale) mixing models and models for upscaling in order to be able to provide meaningful statements for larger areas (forests, catchments, ecosystems).

\section{REFERENCES}

Allen, S. T., Brooks, J. R., Keim, R. F., Bond, B. J., and McDonnell, J. J. (2014). The role of pre-event canopy storage in throughfall and stemflow by using isotopic tracers. Ecohydrology 7, 858-868. doi: 10.1002/eco. 1408

Allen, S. T., Keim, R. F., Barnard, H. R., McDonnell, J. J., and Brooks, R. J. (2017). The role of stable isotopes in understanding rainfall interception processes: a review: interception isotopic effects. WIREs Water 4:e1187. doi: $10.1002 /$ wat2.1187

Allen, S. T., Keim, R. F., and McDonnell, J. J. (2015). Spatial patterns of throughfall isotopic composition at the event and seasonal timescales. J. Hydrol. 522, 58-66. doi: 10.1016/j.jhydrol.2014.12.029

Allen, S. T., Kirchner, J. W., Braun, S., Siegwolf, R. T. W., and Goldsmith, G. R. (2019). Seasonal origins of soil water used by trees. Hydrol. Earth Syst. Sci. 23, 1199-1210. doi: 10.5194/hess-23-1199-2019

Amin, A., Zuecco, G., Geris, J., Schwendenmann, L., McDonnell, J. J., Borga, M., et al. (2020). Depth distribution of soil water sourced by plants at the global scale: a new direct inference approach. Ecohydrology 13:e2177. doi: $10.1002 /$ eco. 2177

Araguás-Araguás, L., Froehlich, K., and Rozanski, K. (2000). Deuterium and oxygen-18 isotope composition of precipitation and atmospheric moisture. Hydrol. Process. 14, 1341-1355. doi: 10.1002/10991085(20000615)14:8<1341::AID-HYP983>3.0.CO;2-Z
We are aware that herein we raise several questions but provide few answers. However, our aim was to "put the finger on the weak spot" and provide impulses. The lack of answers and easy solutions indicates that there are still knowledge gaps at different levels of complexity in isotope-based ecohydrological studies. These gaps create new opportunities and open the way to new research lines to be explored, and that require community efforts and interdisciplinarity approaches as key elements. Taking this road will not make the world less heterogeneous but, at least, it will make it a bit more understandable.

\section{AUTHOR CONTRIBUTIONS}

Both authors equally contributed to the conceptualization and the writing process of the manuscript.

\section{FUNDING}

$\mathrm{MB}$ is funded by the Volkswagenstiftung under the Freigeist program, contract number A122505 (ref. 92889). DP acknowledges the financial support provided by the Department of Agriculture, Food, Environment and Forestry, University of Florence (call Finanziamento di Azioni di Internazionalizzazione - FAI 2020), and the Italian MIUR project (PRIN2017). WATer mixing in the critical ZONe: observations and predictions under environmental changes - WATZON, prot. 2017SL7ABC_002.

\section{ACKNOWLEDGMENTS}

Both authors are grateful to the Editor (Dr. Yunpeng Nie), Dr. James Knighton, and Dr. Erik Oerter for their valuable comments that contributed to significantly improve the original version of this paper.
Barbeta, A., Gimeno, T. E., Clavé, L., Fréjaville, B., Jones, S. P., Delvigne, C., et al. (2020). An explanation for the isotopic offset between soil and stem water in a temperate tree species. New Phytol. 227, 766-779. doi: 10.1111/nph. 16564

Barbeta, A., Jones, S. P., Clavé, L., Wingate, L., Gimeno, T. E., Fréjaville, B., et al. (2019). Unexplained hydrogen isotope offsets complicate the identification and quantification of tree water sources in a riparian forest. Hydrol. Earth Syst. Sci. 23, 2129-2146. doi: 10.5194/hess-23-2129-2019

Benettin, P., Nehemy, M. F., Cernusak, L. A., Kahmen, A., and McDonnell, J. J. (2021). On the use of leaf water to determine plant water source: a proof of concept. Hydrol. Process. e14073. doi: 10.1002/hyp.14073

Berry, Z. C., Emery, N. C., Gotsch, S. G., and Goldsmith, G. R. (2019). Foliar water uptake: processes, pathways, and integration into plant water budgets: foliar water uptake. Plant Cell Environ. 42, 410-423. doi: 10.1111/pce. 13439

Beyer, M., Hamutoko, J. T., Wanke, H., Gaj, M., and Koeniger, P. (2018). Examination of deep root water uptake using anomalies of soil water stable isotopes, depth-controlled isotopic labeling, and mixing models. J. Hydrol. 566, 122-136. doi: 10.1016/j.jhydrol.2018.08.060

Beyer, M., Koeniger, P., Gaj, M., Hamutoko, J. T., Wanke, H., and Himmelsbach, T. (2016). A deuterium-based labeling technique for the investigation of rooting depths, water uptake dynamics, and unsaturated zone water transport in semiarid environments. J. Hydrol. 533, 627-643. doi: 10.1016/j.jhydrol.2015.12.037 
Beyer, M., Kühnhammer, K., and Dubbert, M. (2020). In situ measurements of soil and plant water isotopes: a review of approaches, practical considerations, and a vision for the future. Hydrol. Earth Syst. Sci. 24, 4413-4440. doi: 10.5194/hess-24-4413-2020

Bowen, G. J. (2010). Isoscapes: spatial pattern in isotopic biogeochemistry. Annu. Rev. Earth Planet. Sci. 38, 161-187. doi: 10.1146/annurev-earth-040809-152429

Bowen, G. J., Putman, A., Brooks, J. R., Bowling, D. R., Oerter, E. J., and Good, S. P. (2018). Inferring the source of evaporated waters using stable $\mathrm{H}$ and $\mathrm{O}$ isotopes. Oecologia. 187, 1025-1039. doi: 10.1007/s00442-018-4192-5

Brinkmann, N., Seeger, S., Weiler, M., Buchmann, N., Eugster, W., and Kahmen, A. (2018). Employing stable isotopes to determine the residence times of soil water and the temporal origin of water taken up by Fagus sylvatica and Picea abies in a temperate forest. New Phytol. 219, 1300-1313. doi: 10.1111/nph.15255

Brooks, J. R., Meinzer, F. C., Coulombe, R., and Gregg, J. (2002). Hydraulic redistribution of soil water during summer drought in two contrasting Pacific Northwest coniferous forests. Tree Physiol. 22, 1107-1117. doi: 10.1093/treephys/22.15-16.1107

Cermak, J., Kucera, J., Bauerle, W. L., Phillips, N., and Hinckley, T. M. (2007). Tree water storage and its diurnal dynamics related to sap flow and changes in stem volume in old-growth Douglas-fir trees. Tree Physiol. 27, 181-198. doi: 10.1093/treephys/27.2.181

Charron, G., Robichaud-Courteau, T., La Vigne, H., Weintraub, S., Hill, A., Justice, D., et al. (2020). The deleaves: a UAV device for efficient tree canopy sampling. J. Unmanned Veh. Syst. 8, 245-264. doi: 10.1139/juvs-2020-0005

Cheesman, A. W., and Cernusak, L. A. (2016). Isoscapes: a new dimension in community ecology. Tree Physiol. 36, 1456-1459. doi: 10.1093/treephys/tpw099

Chen, Y., Helliker, B. R., Tang, X., Li, F., Zhou, Y., and Song, X. (2020). Stem water cryogenic extraction biases estimation in deuterium isotope composition of plant source water. Proc. Natl. Acad. Sci. U.S.A. 117, 33345-33350. doi: $10.1073 /$ pnas.2014422117

Dubbert, M., Piayda, A., Cuntz, M., Correia, A. C., Costa e Silva, F., Pereira, J. S., et al. (2014). Stable oxygen isotope and flux partitioning demonstrates understory of an oak savanna contributes up to half of ecosystem carbon and water exchange. Front. Plant Sci. 5:530. doi: 10.3389/fpls.2014.00530

Dubbert, M., and Werner, C. (2019). Water fluxes mediated by vegetation: emerging isotopic insights at the soil and atmosphere interfaces. New Phytol. 221, 1754-1763. doi: 10.1111/nph.15547

Evaristo, J., Jasechko, S., and McDonnell, J. J. (2015). Global separation of plant transpiration from groundwater and streamflow. Nature 525, 91-94. doi: $10.1038 /$ nature 14983

Evaristo, J., Kim, M., Haren, J., Pangle, L. A., Harman, C. J., Troch, P. A., et al. (2019). Characterizing the fluxes and age distribution of soil water, plant water, and deep percolation in a model tropical ecosystem. Water Resour. Res. 55, 3307-3327. doi: 10.1029/2018WR023265

Fatichi, S., Pappas, C., and Ivanov, V. Y. (2016). Modeling plant-water interactions: an ecohydrological overview from the cell to the global scale. WIREs Water 3, 327-368. doi: 10.1002/wat2.1125

Fischer, B. M. C., Frentress, J., Manzoni, S., Cousins, S. A. O., Hugelius, G., Greger, M., et al. (2019). Mojito, anyone? an exploration of low-tech plant water extraction methods for isotopic analysis using locally-sourced materials. Front. Earth Sci. 7:150. doi: 10.3389/feart.2019.00150

Gaj, M., Kaufhold, S., Koeniger, P., Beyer, M., Weiler, M., and Himmelsbach, T. (2017). Mineral mediated isotope fractionation of soil water. Rapid Commun. Mass Spectrom. 31, 269-280. doi: 10.1002/rcm.7787

Geris, J., Tetzlaff, D., McDonnell, J., Anderson, J., Paton, G., and Soulsby, C. (2015). Ecohydrological separation in wet, low energy northern environments? a preliminary assessment using different soil water extraction techniques: ecohydrological separation in northern environments. Hydrol. Process. 29, 5139-5152. doi: 10.1002/hyp.10603

Goldsmith, G. R., Allen, S. T., Braun, S., Engbersen, N., González-Quijano, C. R., Kirchner, J. W., et al. (2018). Spatial variation in throughfall, soil, and plant water isotopes in a temperate forest. Ecohydrology 12:e2059. doi: 10.1002/eco.2059

Hafner, B. D., Tomasella, M., Häberle, K.-H., Goebel, M., Matyssek, R., and Grams, T. E. E. (2017). Hydraulic redistribution under moderate drought among English oak, European beech, and Norway spruce determined by deuterium isotope labeling in a split-root experiment. Tree Physiol. 37, 950-960. doi: 10.1093/treephys/tpx050
Hellmann, C., Große-Stoltenberg, A., Lauströ, V., Oldeland, J., and Werner, C. (2015). Retrieving nitrogen isotopic signatures from fresh leaf reflectance spectra: disentangling $\delta 15 \mathrm{~N}$ from biochemical and structural leaf properties. Front. Plant Sci. 6:307. doi: 10.3389/fpls.2015.00307

Hellmann, C., Rascher, K. G., Oldeland, J., and Werner, C. (2016b). Isoscapes resolve species-specific spatial patterns in plant-plant interactions in an invaded Mediterranean dune ecosystem, edited by L. Cernusak. Tree Physiol. 36, 1460-1470. doi: 10.1093/treephys/tpw075

Hellmann, C., Werner, C., and Oldeland, J. (2016a). A spatially explicit dual-isotope approach to map regions of plant-plant interaction after exotic plant invasion, edited by C. Armas. PLoS ONE 11:e0159403. doi: 10.1371/journal.pone.0159403

Holdo, R. M., Bond, W., Walker, B., Ludwig, D., Holling, C., Peterman, R., et al. (2013). Revisiting the two-layer hypothesis: coexistence of alternative functional rooting strategies in savannas, edited by R. Planque. PLoS ONE 8:e69625. doi: 10.1371/journal.pone.0069625

Huo, G., Zhao, X., Gao, X., and Wang, S. (2020). Seasonal effects of intercropping on tree water use strategies in semiarid plantations: evidence from natural and labelling stable isotopes. Plant Soil 453, 229-243. doi: 10.1007/s11104-020-04477-5

Jackisch, C., Knoblauch, S., Blume, T., Zehe, E., and Hassler, S. K. (2020). Estimates of tree root water uptake from soil moisture profile dynamics. Biogeosciences 17, 5787-5808. doi: 10.5194/bg-17-5787-2020

Juhlke, T. R., Van Geldern, R., Barth, J. A. C., Bendix, J., Bräuning, A., Garel, E., et al. (2021). Temporal offset between precipitation and water uptake of Mediterranean pine trees varies with elevation and season. Sci. Total Environ. 755:142539. doi: 10.1016/j.scitotenv.2020.142539

Knighton, J., Kuppel, S., Smith, A., Soulsby, C., Sprenger, M., and Tetzlaff, D. (2020). Using isotopes to incorporate tree water storage and mixing dynamics into a distributed ecohydrologic modelling framework. Ecohydrology. 13:e2201. doi: 10.1002/eco.2201

Knighton, J., Saia, S. M., Morris, C. K., Archiblad, J. A., and Walter, M. T. (2017). Ecohydrologic considerations for modeling of stable water isotopes in a small intermittent watershed. Hydrol. Process. 31, 2438-2452. doi: 10.1002/hyp. 11194

Knighton, J., Singh, K., and Evaristo, J. (2019a). Understanding catchmentscale forest root water uptake strategies across the continental US through inverse ecohydrological modeling. Geophys. Res. Lett. 47:e2019GL085937. doi: 10.1029/2019GL085937

Knighton, J., Souter-Kline, V., Volkmann, T., Troch, P. A., Kim, M., Harman, C. J., et al. (2019b). Seasonal and topographic variations in ecohydrological separation within a small, temperate, snow-influenced catchment. Water Resour. Res. 55, 6417-6435. doi: 10.1029/2019WR025174

Körner, C. (2019). No need for pipes when the well is dry-a comment on hydraulic failure in trees. Tree Physiol. 39, 695-700. doi: 10.1093/treephys/tpz030

Kulmatiski, A., Beard, K. H., Verweij, R. J. T., and February, E. C. (2010). A depth-controlled tracer technique measures vertical, horizontal and temporal patterns of water use by trees and grasses in a subtropical savanna. New Phytol. 188, 199-209. doi: 10.1111/j.1469-8137.2010.0 3338.x

Kuppel, S., Tetzlaff, D., Maneta, M., and Soulsby, C. (2018). EcH2O-iso 1.0: water isotopes and age tracking in a process-based, distributed ecohydrological model. Geosci. Model Dev. 11, 3045-3069. doi: 10.5194/gmd-11-3045-2018

Marshall, J. D., Cuntz, M., Beyer, M., Dubbert, M., and Kuehnhammer, K. (2020). Borehole equilibration: testing a new method to monitor the isotopic composition of tree xylem water in situ. Front. Plant Sci. 11:358. doi: $10.3389 /$ fpls. 2020.00358

Martín-Gómez, P., Barbeta, A., Voltas, J., Peñuelas, J., Dennis, K., Palacio, S., et al. (2015). Isotope-ratio infrared spectroscopy: a reliable tool for the investigation of plant-water sources? New Phytol. 207, 914-927. doi: 10.1111/nph. 13376

Marzahn, P., Flade, L., and Sanchez-Azofeifa, A. (2020). Spatial estimation of the latent heat flux in a tropical dry forest by using unmanned aerial vehicles. Forests 11:604. doi: 10.3390/f11060604

Mastrotheodoros, T., Pappas, C., Molnar, P., Burlando, P., Hadjidoukas, P., and Fatichi, S. (2019). Ecohydrological dynamics in the Alps: insights from a modelling analysis of the spatial variability. Ecohydrology 12:e2054. doi: $10.1002 /$ eco. 2054 
Moore, J. W., and Semmens, B. X. (2008). Incorporating uncertainty and prior information into stable isotope mixing models. Ecol. Lett. 11, 470-480. doi: 10.1111/j.1461-0248.2008.01163.x

Muñoz-Villers, L. E., Geris, J., Alvarado-Barrientos, M. S., Holwerda, F., and Dawson, T. (2020). Coffee and shade trees show complementary use of soil water in a traditional agroforestry ecosystem. Hydrol. Earth Syst. Sci. 24, 1649-1668. doi: 10.5194/hess-2019-329

Oerter, E., Finstad, K., Schaefer, J., Goldsmith, G. R., Dawson, T., and Amundson, R. (2014). Oxygen isotope fractionation effects in soil water via interaction with cations ( $\mathrm{Mg}, \mathrm{Ca}, \mathrm{K}, \mathrm{Na}$ ) adsorbed to phyllosilicate clay minerals. J. Hydrol. 515, 1-9. doi: 10.1016/j.jhydrol.2014.04.029

Oerter, E. J., and Bowen, G. (2017). In situ monitoring of $\mathrm{H}$ and $\mathrm{O}$ stable isotopes in soil water reveals ecohydrologic dynamics in managed soil systems. Ecohydrology 10:e1841. doi: 10.1002/eco.1841

Oerter, E. J., and Bowen, G. J. (2019). Spatio-temporal heterogeneity in soil water stable isotopic composition and its ecohydrologic implications in semiarid ecosystems. Hydrol. Process. 33, 1724-1738. doi: 10.1002/hyp.13434

Oerter, E. J., Siebert, G., Bowling, D. R., and Bowen, G. (2019). Soil water vapour isotopes identify missing water source for streamside trees. Ecohydrology 12:e2083. doi: 10.1002/eco.2083

Orlowski, N., Breuer, L., Angeli, N., Boeckx, P., Brumbt, C., Cook, C. S., et al. (2018). Inter-laboratory comparison of cryogenic water extraction systems for stable isotope analysis of soil water. Hydrol. Earth Syst. Sci. 22, 3619-3637. doi: 10.5194/hess-22-3619-2018

Orlowski, N., Breuer, L., and McDonnell, J. J. (2016). Critical issues with cryogenic extraction of soil water for stable isotope analysis. Ecohydrology 9, 1-5. doi: $10.1002 /$ eco.1722

Orlowski, N., Pratt, D. L., and McDonnell, J. J. (2019). Intercomparison of soil pore water extraction methods for stable isotope analysis and interpretation of hillslope runoff sources. Hydrol. Process. 33, 2939-2954. doi: 10.1002/hyp. 13539

Parnell, A. C., Inger, R., Bearhop, S., and Jackson, A. L. (2010). Source partitioning using stable isotopes: coping with too much variation, edited by S. Rands. PLoS ONE 5:e9672. doi: 10.1371/journal.pone.0009672

Parnell, A. C., Phillips, D. L., Bearhop, S., Semmens, B. X., Ward, E. J., Moore, J. W., et al. (2013). Bayesian stable isotope mixing models. Environmetrics 24, 387-399. doi: 10.1002/env.2221

Penna, D., Geris, J., Hopp, L., and Scandellari, F. (2020). Water sources for root water uptake: using stable isotopes of hydrogen and oxygen as a research tool in agricultural and agroforestry systems. Agric. Ecosyst. Environ. 291:106790. doi: 10.1016/j.agee.2019.106790

Penna, D., Hopp, L., Scandellari, F., Allen, S. T., Benettin, P., Beyer, M., et al. (2018). Ideas and perspectives: tracing terrestrial ecosystem water fluxes using hydrogen and oxygen stable isotopes-challenges and opportunities from an interdisciplinary perspective. Biogeosciences 15, 6399-6415. doi: 10.5194/bg-15-6399-2018

Penna, D., Stenni, B., Šanda, M., Wrede, S., Bogaard, T. A., Gobbi, A., et al. (2010). On the reproducibility and repeatability of laser absorption spectroscopy measurements for $\delta 2 \mathrm{H}$ and $\delta 18 \mathrm{O}$ isotopic analysis. Hydrol. Earth Syst. Sci. 14, 1551-1566. doi: 10.5194/hess-14-1551-2010

Penna, D., Stenni, B., Šanda, M., Wrede, S., Bogaard, T. A., Michelini, M., et al. (2012). Technical note: evaluation of between-sample memory effects in the analysis of $\delta 2 \mathrm{H}$ and $\delta 18 \mathrm{O}$ of water samples measured by laser spectroscopes. Hydrol. Earth Syst. Sci. 16, 3925-3933. doi: 10.5194/hess-16-3925-2012

Penna, D., and van Meerveld, H. J. (2019). Spatial variability in the isotopic composition of water in small catchments and its effect on hydrograph separation. WIREs Water. 6:e1367. doi: 10.1002/wat2.1367

Pfister, L., and Kirchner, J. W. (2017). Debates-Hypothesis testing in hydrology: theory and practice. Water Resour. Res. 53, 1792-1798. doi: 10.1002/2016WR020116

Poca, M., Coomans, O., Urcelay, C., Zeballos, S. R., Bodé, S., and Boeckx, P. (2019). Isotope fractionation during root water uptake by Acacia caven is enhanced by arbuscular mycorrhizas. Plant Soil 441, 485-497. doi: 10.1007/s11104-019-04139-1

Rinaldo, A., Benettin, P., Harman, C. J., Hrachowitz, M., McGuire, K. J., van der Velde, Y., et al. (2015). Storage selection functions: a coherent framework for quantifying how catchments store and release water and solutes. Water Resour. Res. 51, 4840-4847. doi: 10.1002/2015WR017273
Rodriguez, N. B., and Klaus, J. (2019). Catchment travel times from composite StorAge Selection functions representing the superposition of streamflow generation processes. Water Resour. Res. 55, 9292-9314. doi: 10.1029/2019WR024973

Rothfuss, Y., and Javaux, M. (2017). Reviews and syntheses: isotopic approaches to quantify root water uptake: a review and comparison of methods. Biogeosciences 14, 2199-2224. doi: 10.5194/bg-14-2199-2017

Sánchez-Murillo, R., Durán-Quesada, A. M., Esquivel-Hernández, G., RojasCantillano, D., Birkel, C., Welsh, K., et al. (2019). Deciphering key processes controlling rainfall isotopic variability during extreme tropical cyclones. Nat. Commun. 10:4321. doi: 10.1038/s41467-019-12062-3

Smith, A. A., Tetzlaff, D., and Soulsby, C. (2020). Using StorAge selection functions to assess mixing patterns and water ages of soil water, evaporation, and transpiration. Adv. Water Resour. 141:103586. doi: 10.1016/j.advwatres.2020.103586

Sprenger, M., and Allen, S. T. (2020). What ecohydrologic separation is and where we can go with it. Water Resour. Res. 56:e2020WR027238. doi: 10.1029/2020WR027238

Sprenger, M., Stumpp, C., Weiler, M., Aeschbach, W., Allen, S. T., Benettin, P., et al. (2019). The demographics of water: a review of water ages in the critical zone. Rev. Geophys. 57, 800-834. doi: 10.1029/2018RG000633

Stockinger, M. P., Lücke, A., Vereecken, H., and Bogena, H. R. (2017). Accounting for seasonal isotopic patterns of forest canopy intercepted precipitation in streamflow modeling. J. Hydrol. 555, 31-40. doi: 10.1016/j.jhydrol.2017.10.003

Stumpp, C., Stichler, W., Kandolf, M., and Šimunek, J. (2012). Effects of land cover and fertilization method on water flow and solute transport in five lysimeters: a long-term study using stable water isotopes. Vadose Zone J. 11:vzj2011.0075. doi: $10.2136 /$ vzj2011.0075

Thoma, M., Frentress, J., Tagliavini, M., and Scandellari, F. (2018). Comparison of pore water samplers and cryogenic distillation under laboratory and field conditions for soil water stable isotope analysis. Isotopes Environ. Health Stud. 54, 403-417. doi: 10.1080/10256016.2018.1437034

Troch, P. A., Carrillo, G. A., Heidbüchel, I., Rajagopal, S., Switanek, M., Volkmann, T. H. M., et al. (2009). Dealing with landscape heterogeneity in watershed hydrology: a review of recent progress toward new hydrological theory: landscape heterogeneity and hydrology theory. Geogr. Compass 3, 375-392. doi: 10.1111/j.1749-8198.2008.00186.x

Vargas, A. I., Schaffer, B., Yuhong, L., and Sternberg, L., da S.L. (2017). Testing plant use of mobile vs immobile soil water sources using stable isotope experiments. New Phytol. 215, 582-594. doi: 10.1111/nph.14616

Von Freyberg, J., Allen, S. T., Grossiord, C., and Dawson, T. E. (2020). Plant and root-zone water isotopes are difficult to measure, explain, and predict: some practical recommendations for determining plant water sources. Methods Ecol. Evol. 11, 1352-1367. doi: 10.1111/2041-210X.13461

Wang, H., Si, B., Pratt, D., Li, H., and Ma, X. (2020). Calibration method affects the measured $\delta 2 \mathrm{H}$ and $\delta 18 \mathrm{O}$ in soil water by direct $\mathrm{H} 2 \mathrm{O}$ liquid- $\mathrm{H} 2 \mathrm{O}$ vapour equilibration with laser spectroscopy. Hydrol. Process. 34, 506-516. doi: 10.1002/hyp.13606

Warren, C. P., Kulmatiski, A., and Beard, K. H. (2015). A combined tracer/evapotranspiration model approach estimates plant water uptake in native and non-native shrub-steppe communities. J. Arid Environ. 121, 67-78. doi: 10.1016/j.jaridenv.2015.06.001

Wassenaar, L. I., Coplen, T. B., and Aggarwal, P. K. (2014). Approaches for achieving long-term accuracy and precision of $\delta 18 \mathrm{O}$ and $\delta 2 \mathrm{H}$ for waters analyzed using laser absorption spectrometers. Environ. Sci. Technol. 48, 1123-1131. doi: 10.1021/es403354n

West, A. G., Goldsmith, G. R., Brooks, P. D., and Dawson, T. E. (2010). Discrepancies between isotope ratio infrared spectroscopy and isotope ratio mass spectrometry for the stable isotope analysis of plant and soil waters: discrepancies between IRIS and IRMS analysis of plant and soil waters. Rapid Commun. Mass Spectrom. 24, 1948-1954. doi: 10.1002/ rcm.4597

West, J. B., Bowen, G. J., Dawson, T., E., and Tu, K. P. (eds.). (2010). Isoscapes: Understanding Movement, Pattern, and Process on Earth Through Isotope Mapping. Dordrecht: Springer.

West, J. B., Sobek, A., and Ehleringer, J. R. (2008). A simplified GIS approach to modeling global leaf water isoscapes. PLoS ONE 3:8. doi: 10.1371/journal.pone.0002447 
Wickert, A. D., Sandell, C. T., Schulz, B., and Ng, G.-H. C. (2019). Opensource arduino-compatible data loggers designed for field research. Hydrol. Earth Syst. Sci. 23, 2065-2076. doi: 10.5194/hess-23-206 5-2019

Wilusz, D. C., Harman, C. J., and Ball, W. P. (2017). Sensitivity of catchment transit times to rainfall variability under present and future climates. Water Resour. Res. 53, 10231-10256. doi: 10.1002/2017WR 020894

Zhang, Z. Q., Evaristo, J., Li, Z., Si, B. C., and McDonnell, J. J. (2017). Tritium analysis shows apple trees may be transpiring water several decades old. Hydrol. Process. 31, 1-6. doi: 10.1002/hyp.11108

Zuecco, G., Amin, A., Frentress, J., Engel, M., Marchina, C., Anfodillo, T., et al. (2020). A comparative study of plant water extraction methods for isotopic analyses: scholander-type pressure chamber vs. cryogenic vacuum distillation. Hydrol. Earth Syst. Sci. Discuss. 1-23. doi: 10.5194/hess-2020-446

Conflict of Interest: The authors declare that the research was conducted in the absence of any commercial or financial relationships that could be construed as a potential conflict of interest.

Copyright (c) 2021 Beyer and Penna. This is an open-access article distributed under the terms of the Creative Commons Attribution License (CC BY). The use, distribution or reproduction in other forums is permitted, provided the original author(s) and the copyright owner(s) are credited and that the original publication in this journal is cited, in accordance with accepted academic practice. No use, distribution or reproduction is permitted which does not comply with these terms. 